\title{
Energy I-Corps Electron Beam (EB) Potential for International Trade of Logs
}

\section{Cohort - 11 Team EB Treement}

\author{
Michael Geelhoed \\ Engineering Physicist \\ Fermi National Accelerator Laboratory \\ Dr. Nathan Siegert \\ Forest Entomologist
}

US Forest Service, State \& Private Forestry, Eastern Region, Forest Health Protection

\section{Scott Schirmer}

Nursery \& Northern Field Office Section Manager, State Plant Regulatory Official Illinois Department of Agriculture, Bureau of Environmental Programs 


\section{Disclaimer}

This work was prepared as an account of work sponsored by an agency of the United States Government. Neither the United States Government nor any agency thereof, nor any of their employees, nor any of their contractors, subcontractors or their employees, makes any warranty, express or implied, or assumes any legal liability or responsibility for the accuracy, completeness, or any third party's use or the results of such use of any information, apparatus, product, or process disclosed, or represents that its use would not infringe privately owned rights. Reference herein to any specific commercial product, process, or service by trade name, trademark, manufacturer, or otherwise, does not necessarily constitute or imply its endorsement, recommendation, or favoring by the United States Government or any agency thereof or its contractors or subcontractors. The views and opinions of authors expressed herein do not necessarily state or reflect those of the United States Government or any agency thereof, its contractors or subcontractors.

\section{Acknowledgements}

This work was supported by the Assistant Secretary for Energy Efficiency and Renewable Energy. Building Technologies Office, of the U.S. Department of Energy (DOE) under Contract No. DE-AC02-07CH11359 as part of the Energy I-Corps program, a key initiative of DOE's Office of Technology Transitions.

The authors would like to thank the Energy I-Corps program team and instructors for the opportunity to participate, your patience, and your guidance. We would also like to thank the many people who were willing to share their knowledge and expertise with us as we explored this exciting market opportunity for the technology. 


\section{Table of Contents}

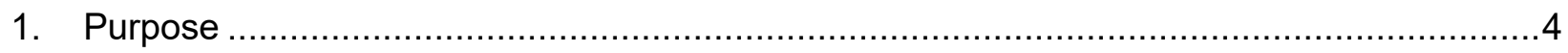

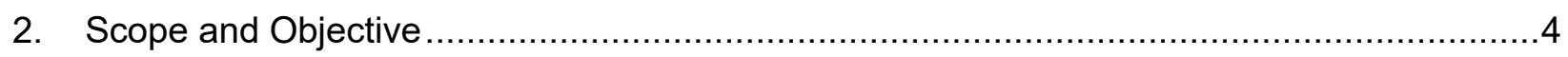

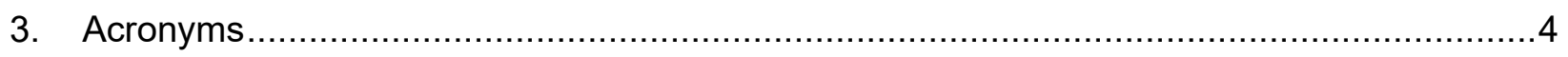

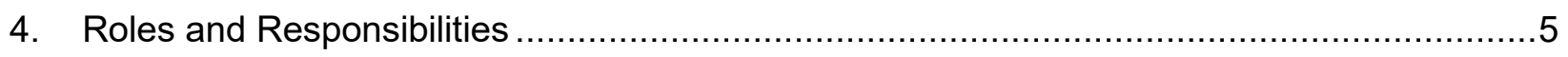

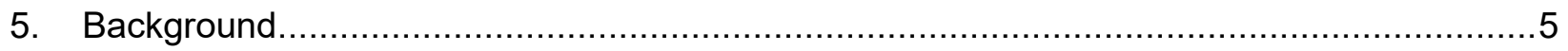

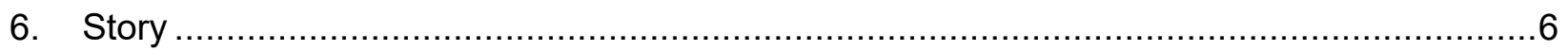

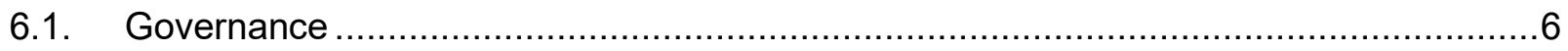

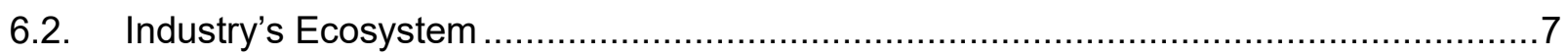

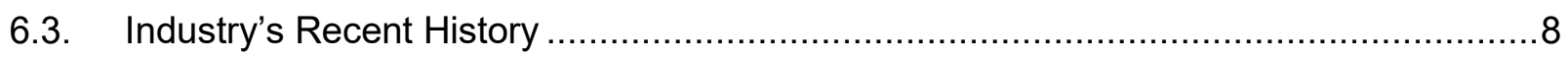

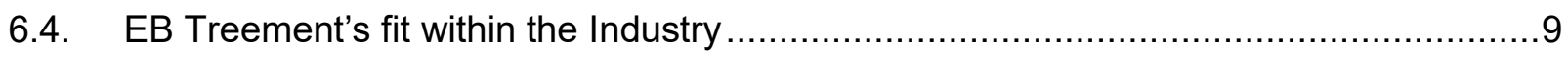

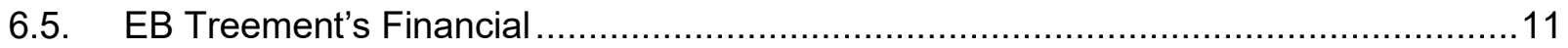

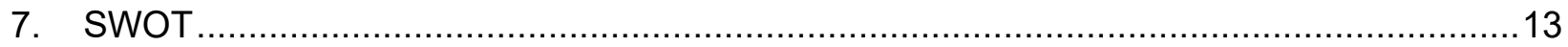

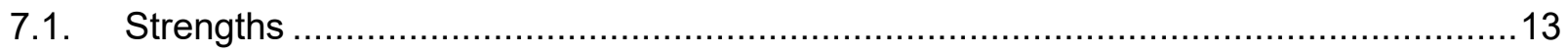

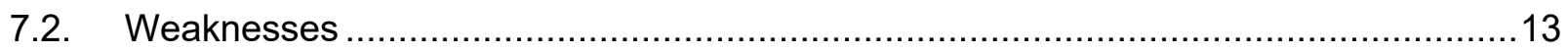

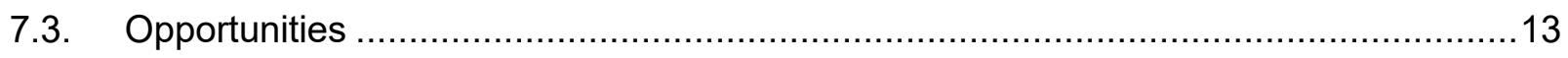

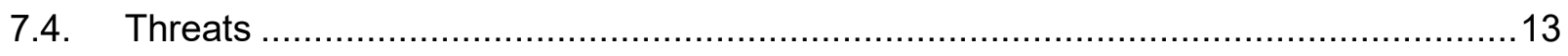

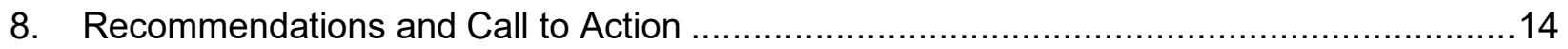

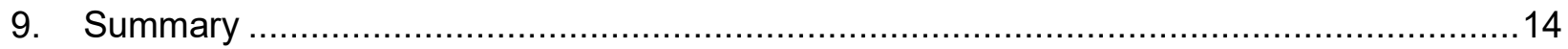

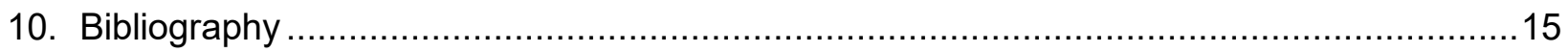




\section{Purpose}

The purpose of this document is to capture the potential from Fermilab's "Team EB Treement" at the DOE Energy I-Corps program. Energy I-Corps, a key initiative of the Office of Technology Transitions, pairs teams of researchers with industry mentors for an intensive two-month training where the researchers define technology value propositions, conduct customer discovery interviews, and develop viable market pathways for their technologies [1]. The team was composed prior to the Energy I-Corp program; however, the program was a catalyst for education and information exchange between the team members and stakeholders, customers, and regulators. These exchanges were captured in the evolution of a Business Model Canvas (BMC) and a Value Proposition (VP). The BMC and VP underwent numerous transformations based on feedback from the conversations between members of the team and forest or agriculture industry stakeholders and the program instructors.

\section{Scope and Objective}

The scope of the program was to determine the true customer of this technology platform, research the financial obligations associated with the technology, and determine the most efficient approach based on customer and industry demand. Based on these key attributes, the objective was then to define the strengths, weaknesses, opportunities, and threats and to provide a potential path forward and call to action.

The team is intimate that every state in the US has at least one imported invasive forest pest, but the program gave us a simple question, "Who cares enough to pay?" Unfortunately, we could not directly answer this question. As harsh as it was to reflect on the truth, there are too many world problems to solve over invasive species. Invasive species collectively pose a significant impact on the forest products industry, but individually to national security, the monetary value is relatively small.

If this technology is going to be accepted, our objective is to understand the governance in which our technology can play a significant role. Our team then will research and understand the industry's ecosystem. Lastly, we will identify and defend the purpose and benefits behind adopting our technology to other processes the industry has historically used. This document provides a summary and an evidencebased path forward for the technology and application.

\section{Acronyms}

\begin{tabular}{|l|l|}
\hline APHIS & Animal Plant Health Inspection Services (USDA) \\
\hline BMC & Business Model Canvas \\
\hline DOE & Department of Energy \\
\hline CBP & Customs and Border Patrol \\
\hline EB & Electron Beam \\
\hline EPA & Environmental Protection Agency \\
\hline EU & European Union \\
\hline FAO & Food and Agriculture Organization \\
\hline IDOA & Illinois Department of Agriculture \\
\hline ISPM & International Standard for Phytosanitary Measures \\
\hline MB & Methyl Bromide \\
\hline NPPO & National Plant Protection Organization \\
\hline NREL & National Renewable Energy Laboratory \\
\hline
\end{tabular}




\begin{tabular}{|l|l|}
\hline SPRO & State Plant Regulatory Official \\
\hline SPHD & State Plant Health Director \\
\hline UN & United Nations \\
\hline USDA & United States Department of Agriculture \\
\hline USFS & US Forest Service (USDA) \\
\hline VP & Value Proposition \\
\hline
\end{tabular}

\section{Roles and Responsibilities}

The team was comprised of three key members. From Fermilab, Michael Geelhoed was the Principal Investigator and the Entrepreneurial Lead. The team had two industry members: Scott Schirmer of the Illinois Department of Agriculture (IDOA) and Nathan Siegert, PhD, of the United States Forest Service (USFS). Both members served as direct liaisons to members of the forest industry for interviews and discussions.

From the program, the NREL team was comprised of numerous instructors and mentors. Their insight and lectures resonated with the team throughout the program. All contributions were valued, but a few of those that interacted the most should be highlighted: Tom Teynor, Dr. Russell Carrington, and Jean Redfield.

\section{Background}

Prior to the program, the team was focused on using this technology and application to sterilize logs to fight against invasive species. Our initial research looked over the benefits of this application for the log and lumber industry. The team has a broad-based knowledge that invasive species create billions of dollars' worth of damage as a large factor in the death of forest vegetation and pose a direct risk towards forest fires.

The environmental impact created by these forest fires, beyond monetary damage, is the release of carbon into the atmosphere. Global forest fires are a key factor of pyrogenic carbon production of an estimated 2.2 Pg of carbon per year to the atmosphere. [2] We also discovered that lumber compared to other building materials has a lower carbon footprint during production. Concrete and steel are staples of building materials, however both materials have higher carbon footprints than lumber. [3] If green building programs want to endorse lumber as a sustainable environmental building material to provide a healthier world, then we should ensure ourselves that these resources are readily available. [4]

With more research beyond the Emerald Ash Borer in the Midwest, we soon discovered there were numerous combinations of forest invasive and tree species that could benefit from this technology. This concept started as a method for invasive species mitigation based on early detection from the international trade of wood resources while being imported. We focused our efforts on the application benefits to the entire country on an early detection platform. The team discovered a request for proposals from the USDANIFA Tactical Sciences for Agricultural Biosecurity. This program area priority focuses on increasing our national capacity to prevent, rapidly detect, and respond to biological threats to the U.S. agriculture and food supply at the regional and national levels across all sectors.

While writing the proposal, the team was able to reach out to numerous state regulating officials spanning from New York to Colorado. In our conversations we were invited to the Central Plant Board annual conference in 2020 to discuss our proposed research. Ultimately the team's research and proposal was supported by 10 states, the National Plant Board and the USDA Forest Product Laboratory for using high energy electron beams to sterilize forest invasive species that dwell just below the surface of the bark at the surface of log. [5] 
Unfortunately the reviewers denied funding for the proposal. One primary concern was the financial recovery of this technique where the team should provide some assurance that the end users will be able to adopt the procedures developed. What was unknown is who would pay for this treatment and what would allow to make this treatment operational. With this response to the proposal it was natural for the team to apply for the Energy I-Corp program.

\section{Story}

\subsection{Governance}

The team verified through our continued research and conversations with government officials that the industry's ecosystem for agriculture foreign trade is a two-way street. Trade agreements between countries are established through the countries self-identified National Plant Protection Organization (NPPO). For the United States, it's the USDA, and in particular for international trade the APHIS/PPQ office conducts international agreements. The trade agreements are discussed and signed by representatives with foreign government agencies.

These terms and conditions are mainly dictated by the country that is accepting the goods or products. This is based on the principle that the accepting country is taking the majority of the risk of invasive species. Members from APHIS/PPQ confirmed these agreements are traditionally based on a "what's good for you is good for us" mentality when dealing with the sterilization treatment schedules. Thus, the treatment schedules are based on scientific research and development with large data sets and are mutually accepted between the countries.

The majority of countries that have agreements follow the Food and Agriculture Organization (FAO) of the United Nations (UN). The FAO has written documents called the International Standard for Phytosanitary Measures (ISPM). Numerous treatment schedules are based on the product and commodities of trade. These documents are directly related to the control measures the USDA-APHIS references for importing fruits and vegetables into the US along with other countries. In this context, phytosanitary treatments via irradiation are acceptable for certain products and schedules. The objective of phytosanitary treatments is to prevent the introduction or spread of regulated invasive pests. Our team's main hypothesis was electron beam sterilization was an effective means to treat raw wood commodities upon importation and also to explore other markets until they are eliminated.

In ISPM 15, standards are established for the regulation of wood packaging materials in international trade. [6] ISPM 18 establishes standards for the use of irradiation as a phytosanitary measure for agricultural products such as fruits and vegetables and lists adequate irradiation doses for particular invasive species. [7] ISPM 28 provides the basis for the international approval of phytosanitary treatments. [8] The team focused on exploring our technology and application by merging these two ISPMs, 15 and 18, to include the wood packaging materials phytosanitary measure of irradiation to invasive species categories following the ISPM 28 as a checklist.

We talked to pallet manufacturers and distributors for creating wood pallets and wood packaging materials. These products already endure a very lengthy process designed for heat treatment (HT) of the wood to obtain material property characteristics. HT is designed to reduce moisture in the manufactured low-grade wood and is not intended for phytosanitary measures. This treatment effectively provides the same results as phytosanitary measures given its process exceeds some phytosanitary measures.

We also discussed with wood utilization specialists and members of the industry that processed wood or lumber is not the location for this technology. With a low possibility of impractical use, EB does not fit the industry need, while HT satisfies the industry need for the regulations set forth. From here, the team explored further back in the supply chain within the industry's ecosystem and began to focus on lumber's raw material in the form of logs. 


\subsection{Industry's Ecosystem}

The team researched the industry as much as public references would allow through the United States Department of Agriculture (USDA) and the Animal Plant Health Inspection Services (APHIS), specifically the branch that regulates international trade of log resources from Plant Protection and Quarantine (PPQ). Therefore, the Energy I-Corps program prompted the team to think about the true customer of this technology, its benefactors, stakeholders, and the potential impacts to the ecosystem.

The team started to research foreign trade of logs from US forests. We eventually established our graphical ecosystem for international log trade shown in Figure 1. There are combinations of landowners, tree harvesters, log yards, and timber buyers that make up the front end of the revenue stream. Some of these roles are combined creating a vertical integration through the value chain. These various combinations of roles funnel toward an international buyer. The international buyers are the end customer that bear the costs associated with exporting the wood commodities through an invoice from the seller. The seller then is responsible for the product getting to the customer. In our continued conversations with government members, we confirmed that the same process is concurrently happening from the foreign country's perspective.

The team was able to talk with many individual members of state agencies that interact with log yard owners and sellers. Here in Illinois, these log yard owners are in the southern portion of the state, and the process for exporting logs is very similar to the remainder of the country. This process includes a methyl bromide treatment schedule, which is regulated by the Environmental Protection Agency (EPA). We connected with fumigation services companies through the yard owners, and one conversation was truly revealing. While the team assumed that our technology and application would rival the traditional treatment modality, the fumigator expressed high interest in adopting the technology themselves. Our team had assumed we were creating competition for their business.

The fumigator expressed concern of their traditional methods given that they are forced to deal with a deadly chemical that has serious criminal consequences if they fall out of highly regulated standards. These fumigation companies are embedded with an operational risk which they are highly interested in reducing. EB Treement does not require these deadly fumigants. The fumigator in our region noted other restrictions such as the limited quantity of fumigants annually acquired and the threshold of efficacy of the base temperature of the logs.

The EPA annually limits the purchasing capacity of Methyl Bromide (MB) for fumigation sites. This limited amount of fumigant restricts the throughput of certain commodities from the site. When discussing with local fumigators, we calculated the annual throughput of 40,000 logs per site. In addition to restrictive chemicals, the material to be fumigated must be at a certain temperature prior to the application or procedure. If these recorded temperatures are not achieved, additional quantities of MB must be used, or additional time is required for proper treatments. In either case this substantially increases the process time or limits the annual throughput. This was encouraging; however, we knew we needed more information to confirm this interest. Our industry mentors arranged for additional discussions with the industry's ecosystem in the New England area.

In the New England (NE) area where there are an estimated $100 \log$ yards, we continued our discussions. Unfortunately, documenting all these log yards is nontrivial. Most of them don't utilize the technology incorporated with the dot coms of today. The industry relies heavily on the word-of-mouth mentality and phone numbers. Some log yards are not established with a website or email address, so research proved difficult for the team, but we are grateful for those members of the industry we were able to talk to. 


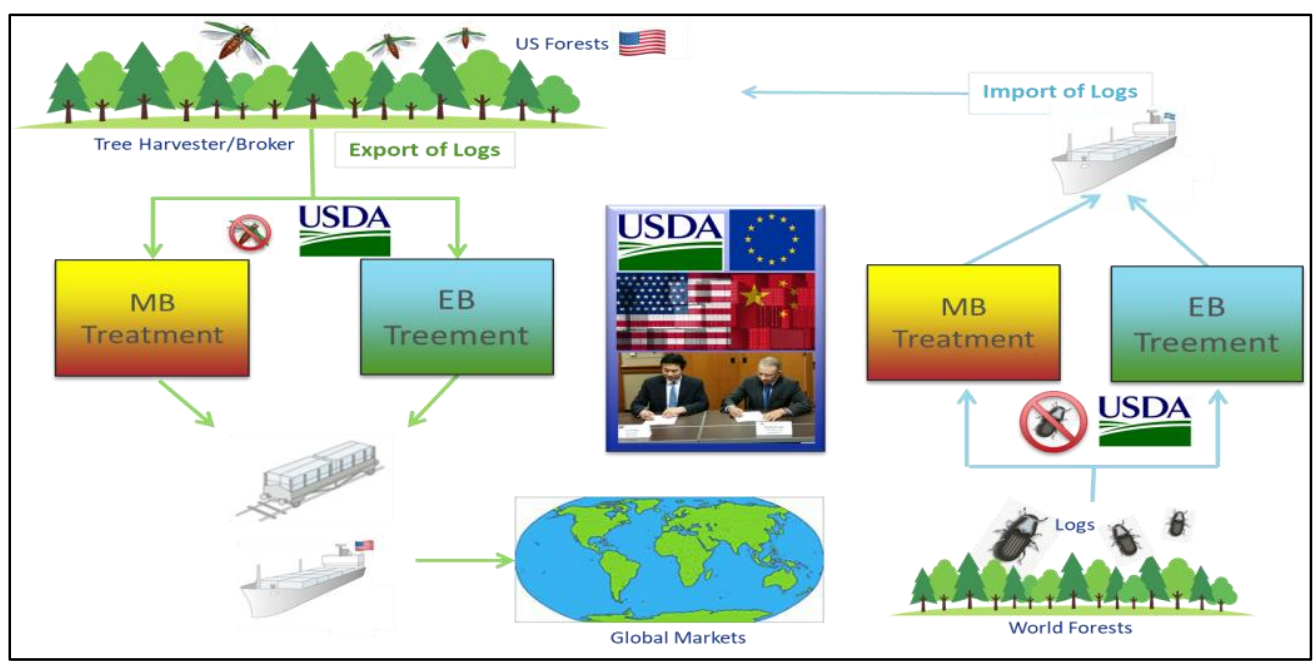

Figure 1: EB Treement's Industry Ecosystem map [9]

\subsection{Industry's Recent History}

The team was able to gather the details of the NE area history and the industry. The NE area was primarily selling internationally to the European Union based on the location and the species of trees and logs available in the region as shown in Figure 2. The industry was doing quite well over the last few decades. The team identified three cyclic patterns when discussing with our interviewees in this region.

The first oscillation was based on the United States changing regulations. There was an apparent 4-to8-year pattern that opened or closed opportunities within the market. The seasonal fluctuation was an annual phase. This change was more predictable given the seasonal forecast of species that thrived in the forests and those commodities of high surplus. The last, more unpredictable influence, was the aesthetically pleasing hardwoods. There were flashes of market demand of designer hardwood species not easily in 'stock,' and the market surged. We understood from our conversations that if there were an introduction of a new treatment process, we would likely take the existing weaknesses and reform them with new technology to accommodate the industry's eventual need.

Once the EU decided to not accept any fumigated logs into their region, the burden was on the log yards and the NE biological ecosystem. The harvesters and log yards struggled to find buyers of their product and had to revert to other methods for phytosanitary measures. The method of choice was debarking the logs prior to shipping while obtaining customers from Asian countries. The local state agencies would grant a certificate worthy of international trade based on this technique within ISPM standards. This certificate would follow the shipment to pass a customs border inspection. The consequences of debarking logs yield quality loss of the material. The logs would quickly decline in value during shipping from warping, staining, and the decreased water moisture content.

With the EU decision to reject importation of fumigated logs, trading decreased and fumigation services in the NE area ceased to exist. The nearest geographical location of a fumigation site was as far south as Baltimore, MD. It was recently discovered during our conversation with the State Plant Health Director (SPHD) of the area that this facility was closing its doors. 


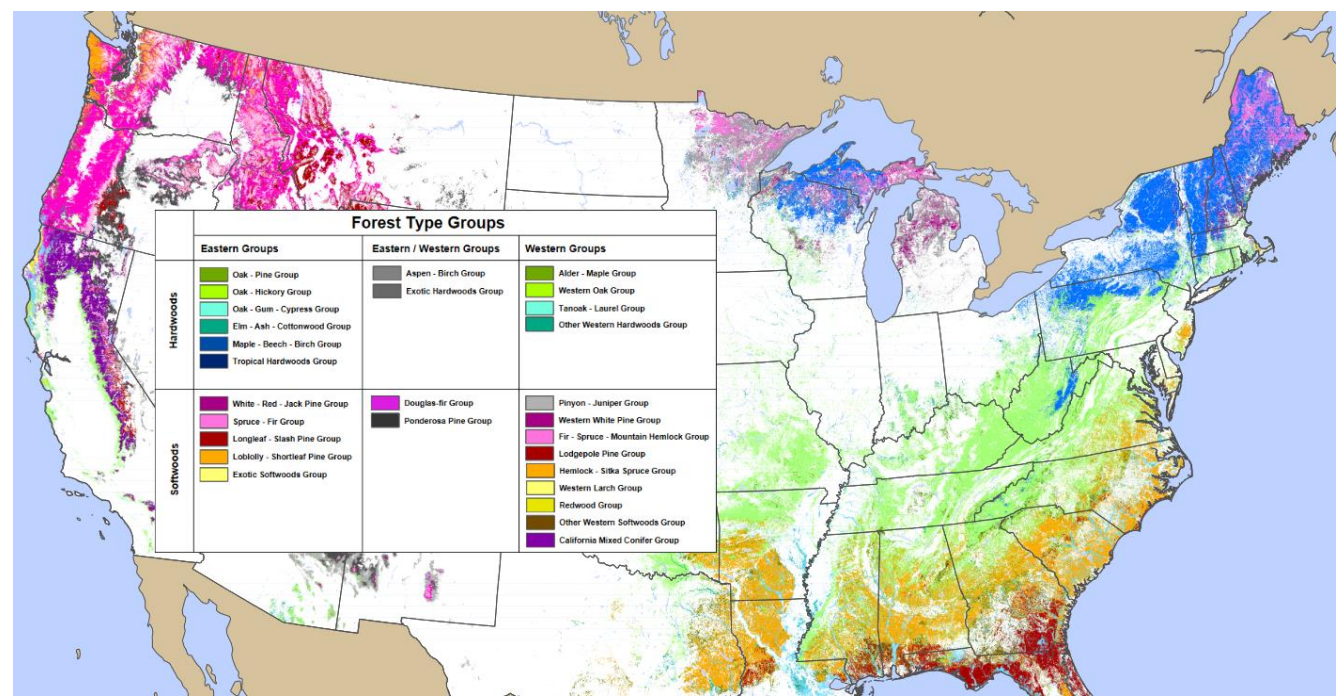

Figure 2: US Forest map by Type and Groups [10]

\subsection{EB Treement's fit within the Industry}

The team at this point realized that EB Treement has a degree of potential from the traditional fumigation treatment, however the team needed to understand its implication within the industry's ecosystem. Our industry mentors promoted researching the areas in the Midwest and eventually in the South. However, based on the program's method, we needed to understand what the product or service we were providing. Our team's mentality had to shift from our research to the commercialization aspect of our technology. From there we looked within our research to identify the resource that could gain the most from this treatment: hardwoods.

Through our later conversations, we confirmed that the NE area is the primary location for hardwoods from the United States. This region not only has the tree species best suited for the application but is also dominated by private companies that own the land shown in Figure 3. These log yards need a treatment schedule that limits damage to their product, and they are seeking alternative solutions.

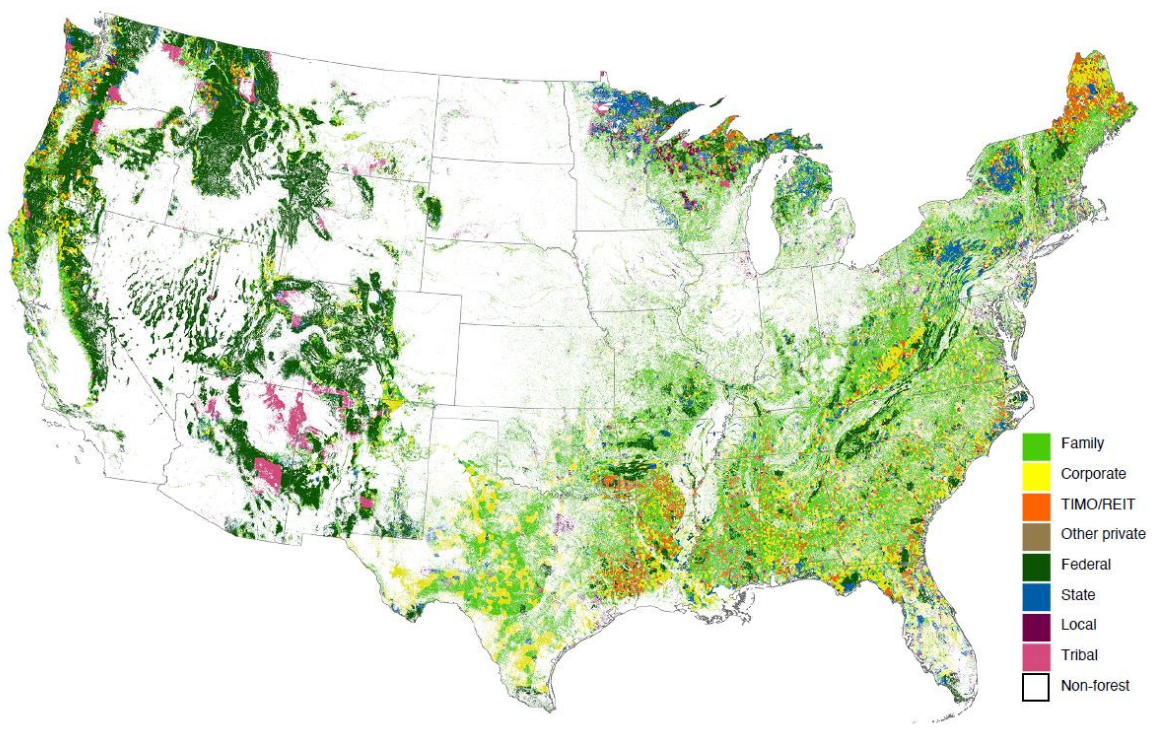

Figure 3: Forest Ownership in the US [11] 
In this region, the industry previously used fumigation, the current method in the Midwest and southern regions. In those regions, the vertical integration and the logistics were practically identical to those in the NE area. From landowners, harvesters, and log yards, the international buyers would pick and choose their logs for trade.

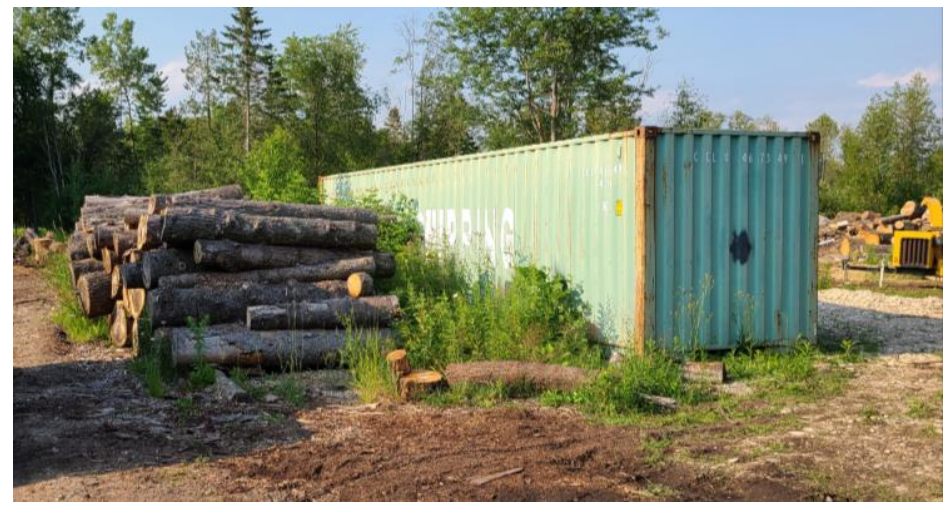

Figure 4: Typical log yard with available product

Once the logs were sold to the international buyer, the shipment went through a logistics company towards the global markets arranged by the seller of the vertical integration. The responsible party would schedule the logs for loading into containers locally at the log yard. Then the trucking company would deliver these containers to the nearby fumigation facility. The logs would undergo the fumigation process and the logistics company would arrange for continued shipping from the fumigation site to the shipyard. Once a ship arrived in port, the containers would be loaded onto the container ship. In some situations, these containers would be placed on train cars and transported across continent for eventual shipping.

In either region, logistics are a large component that factors into whether the EB Treement process adds value to the current method. The current method of international log trade is based on number of containers at a time that fit within the weight restriction of both the ship, rail and trucking capacities. Between the three methods of transportation, the team discovered the rates of transporting are significantly different between road versus rail or ship from the freight forwarders.

According to those in the industry in the NE area, the dollar per mile for a container for oceanic shipping and cross-continental rail is estimated to be $\$ 0.11 /$ mile, while the cross-continent trucking cost rate was $\$ 2 /$ mile for the same size and weight container. This discrepancy placed an emphasis on the potential facility's location to be best utilized near the forests yet close to the rail system for optimal shipping to foreign countries.

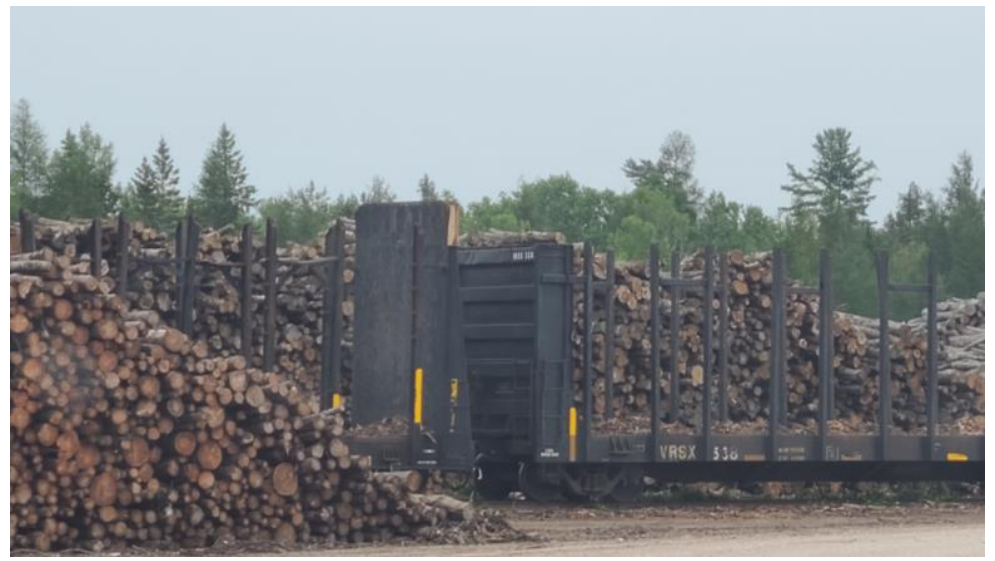

Figure 5: Logs being prepared for local rail 


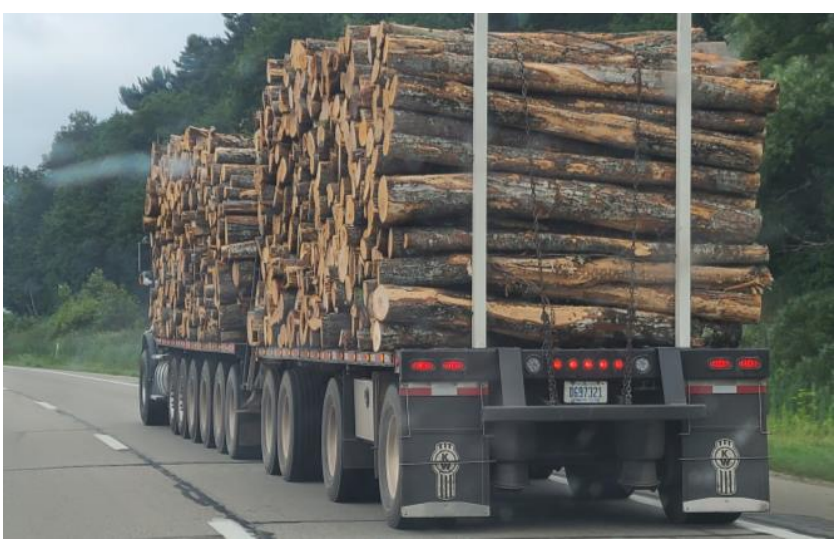

Figure 6: Trucking freshly cut logs from the log yard

\subsection{EB Treement's Financial}

We had to standardize our units for the sake of comparisons of the two methods when dealing with financial comparison. Based on our customer interviews, we averaged the standard international purchase of 20 containers of logs. Each container would then contain approximately $30 \operatorname{logs}$ and each log is based on a 12-inch diameter at a length of 10 feet. Considering these conversational standards, each purchase would be subject to fumigation via Methyl Bromide to pass phytosanitation control.

For the specific commodity discussed, high value hardwoods, MB fumigation of these logs could easily take five days to complete if all constraints are properly achieved. Not only is this process time consuming, but its upfront resources are also limited and restrictive for our standard international purchase. This upfront resource is captured in the efforts to gain acceptable initial conditions of the logs prior to $\mathrm{MB}$ fumigation. These logs are required to be at a base temperature of at least $40^{\circ} \mathrm{F}$ prior to and during the fumigation duration. [12] This sub-cost impact is not calculated in the comparison such as cost of heating the closed containers or structure, or the property tax to conduct the 5 day process.

Our process, though, would take approximately two days to complete for the same standard international purchase. The process of treating these logs is independent of the internal temperature of the commodity, and the process is not quantized to a container full of logs. Our treatment allows for year round applications where the supply can match the demand of all fluctuations. In addition, this treatment process is conducted on an individual log basis and provides more flexibility in quantities purchased. The logistical solution to this improvement is then allowing open trucks as shown in Figure 6 to transport logs to the treatment facility. When the EB treatment is completed, the logs would be transferred to the international shipping containers and tagged with the phytosanitary certificate at the treatment facility.

This single log treatment process was discussed with machinery manufacturers to get a sense of the industry's capability. Existing log spinning machines would be modified, and a particle accelerator take the place of their traditional tooling. We were able to discuss the rotational speed of logs that are well within our requirements. 


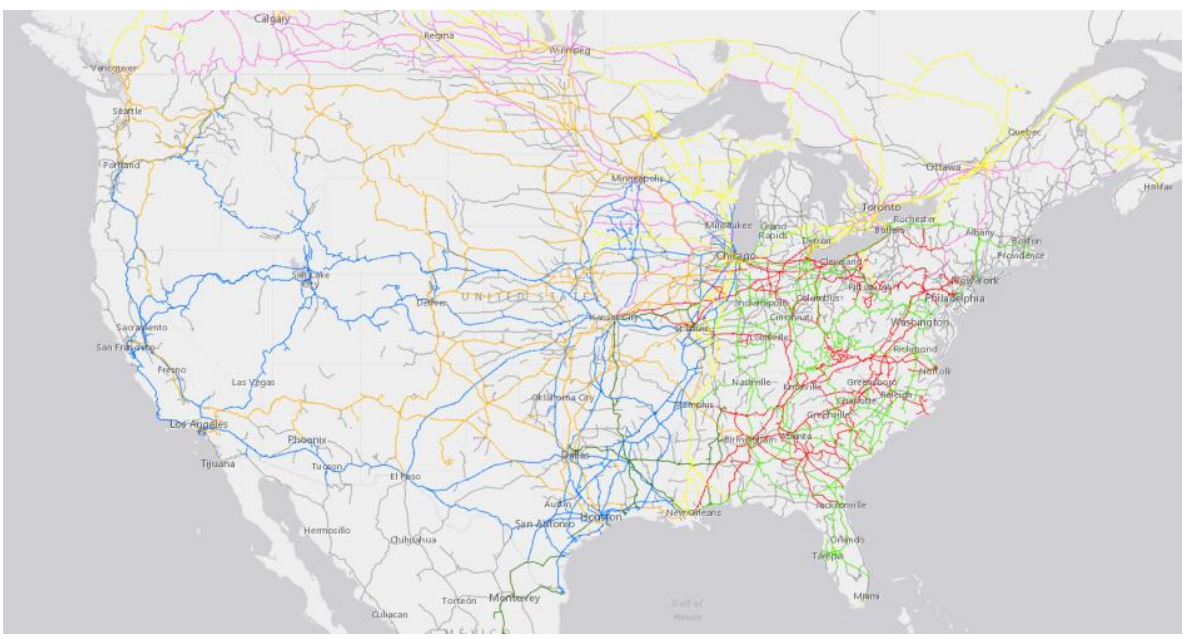

Figure 7: National Rail Network Map [13]

Refocusing on the logistics component of our treatment modality, as shown in Figure 7, the US rail network does reach the NE area and extends to the major ports on both coasts for international shipping. The team investigated optimizing the potential location of a EB Treement facility between the log yards and the rail network that is financially sound. The team then incorporated the tree species and owners, Figure 2 and Figure 3, into the analysis. While one facility will not be able to handle the flux of logs entirely from the NE area, even at maximum capacity, the optimized facility location in this region was placed near Augusta, ME. This was based on average mileage to the log yards in the region, property taxes for the facility, and the full shipping costs of containers. Through the guidance of the program, our financial analysis took into consideration the revenue stream, cost of goods and services, and the operating expenses associated with such a facility. With current APHIS irradiation treatment schedules for the invasive species, the estimated gross profit margin ranged from 33\% to $45 \%$ dependent on the number of operating shifts per day.

In addition to the conventional facilities and building infrastructure, we compared the cost to complete a fumigation treatment of 20 containers for our standard international purchase. Our fumigator's quote to the seller was estimated at $\$ 24,000$ (five days). For the same number of logs within those containers (600), the cost from EB Treement is estimated at $\$ 18,000$ (two days).

Therefore, towards the end of our analysis and the Energy I-Corps program, we were able to create metrics to our value proposition: For logs exporters that require phytosanitary treatment for trade, EB Treement provides a reliable electron beam treatment schedule all year round, shortening the treatment time to $40 \%$ and reduces the cost by $25 \%$.

\begin{tabular}{|l|l|l|l|l|}
\hline \multicolumn{5}{|c|}{ Illustrative Revenue/Cost Model } \\
\hline $\begin{array}{l}\text { Operation of 4000 } \\
\text { hrs/yr or } \sim 70,000 \text { logs }\end{array}$ & $\begin{array}{l}\text { Annual } \\
\text { (2 shifts) }\end{array}$ & Variable Costs & Annual Fixed Costs & Gross Profit \\
\cline { 2 - 5 } & $\$ 2,105,000$ & $\$ 1,046,000$ & $\$ 175,000$ & \\
\cline { 2 - 4 } & & $\$ 884,000$ \\
\cline { 3 - 4 } & & Gross Profit Margin \\
\cline { 3 - 4 } & & $42 \%$ \\
\hline
\end{tabular}

Annual Revenue is based on unit price reduction matching to $25 \%$ cost savings (simple pass through)

Variable cost $=$ Labor and Utilities varied by volume process

Annual Fixed Cost = Facility Licensing Fees, Lease/Mortgage Costs, General Administration Costs

Table 1: EB Treatment Illustrative Revenue/Cost Model 


\subsection{Strengths}

One strength of EB Treement's application is the reduced risk and cost from traditional MB fumigation. As noted above, EB Treement provides a reliable electron beam treatment schedule all year round, shortening the treatment time to $40 \%$ and reduces the cost by $25 \%$. MB is a risky business with dire consequences if done incorrectly. Mitigating the chemical from a sterilization process while maintaining effectiveness is the fundamental strength of the EB application. The reduced operating cost is split between the consumable chemicals, conventional facilities and building infrastructure to obtain initial treatment conditions. The flexible, year-round available and shortened application schedule of EB compared to MB increases its value for the fluctuating industry demand and turnaround time. With an appropriately placed facility and slightly modified and improved logistics, EB treatment serves as an improvement across the entire process of international trade of logs.

\subsection{Weaknesses}

Logistical modification is the primary weakness of the EB Treement application. This technology requires the industry to modify the order in which containers are loaded with logs. The treatment process is not a long batch process but an individual treatment to the log. Therefore, logs will be better suited in transportation vehicles shown in Figure 6 to be sterilized at a nearby facility. Then, at the facility, $\operatorname{logs}$ are loaded in containers and transported to their final destination. In discussing this modification with $\log$ yards, this modification might be acceptable given shipping containers, trucks, and truck drivers are harder to arrange than their own.

Most other new treatment technologies discovered in our interviews would also include potentially substantial modifications to existing facilities and/or processes. Our interviews suggest the industry's hesitancy to make a paradigm shift for log treatment which creates self-nominated limitations. Until the threats mentioned below are mitigated, accepting EB treatment as the economically viable new treatment logistic modification will remain a weakness in advancing this technology and application.

\subsection{Opportunities}

The obvious opportunity is the direct reduction or mitigation of MB use. There is international outreach to find alternatives to $\mathrm{MB}$ fumigation, and electron beam irradiation provides this alternative. Approximately $25 \%$ of the world use of $\mathrm{MB}$ is on wood products and recommendations favor the use of EB technology as a replacement of $\mathrm{MB}$. The $\mathrm{MB}$ fumigation process requires additional consumed resources that $\mathrm{EB}$ does not.

The mitigation of using MB improves the environmental justice for the surrounding communities of these facilities. Facilities that reduce the annual amount of MB purchased inherently reduces the risk of an accident near their communities. The energy efficiency of heating logs prior to fumigation is not good practice compared to year-round EB treatment. Concurrent to year-round opportunity for EB is its flexibility. Beyond the base temperature for the commodity, EB treatment accommodates the market fluctuation. Forecasting and predicting the throughput will be less of a risk to the industry.

\subsection{Threats}

Unfortunately, there are numerous threats to EB Treement discovered in the later stages of our customer interviews. The industry and regulators are more focused on alternative fumigants given the current service providers are prepared for a simple chemical replacement to MB. Our conversations of alternatives suggest more research is being invested on this path forward than alternative technologies. 
In conversation with the USDA, EB treatment is better suited for the perishable commodities industry, which has yet to fully adopt this process domestically. International regulators are focused on which products EB sterilization would serve a better purpose before re-prioritization of international efforts. Until public and government perception can fully accept the benefits of EB treatments, logs will have to remain toward the bottom of the list.

In a parallel threat, the primary implementation is focused in the NE area with reestablishing trade to the European Union. The current implementing EU regulation is scientifically unjustified in its requirements for irradiation. The regulation poses an impossible scientific solution for high-energy electron particle accelerators. [14] The optional statements focus on the bark of a log where this method is not energy efficient. Based on their fundamental purpose these statements are in disagreement. There is research and data that can provide the necessary information for sound regulations.

\section{Recommendations and Call to Action}

The team here provides recommendations and actionable items for agencies that elect to pursue EB sterilization as a feasible solution.

1. We recommend an extensive study be conducted in which numerous combinations of forest and insect species are evaluated for EB sterilization from various geographical locations. This data set should be all-inclusive to the highest risk forest invasive and the commodity in which it favors. The experimental data should be generated from a benchtop study, and if signs of success are evident, expanded to a full-scale demonstration unit.

2. The policy and regulatory framework could be modified to provide a reasonable justification to the treatment schedules as compared to this dataset. The current treatment requirement is not consistent with other treatment schedules for the identical commodity. The data and results should be transformed into sensible and potential regulations.

3. Once the results and potential regulations are constructed, the responsible NPPO should elevate the results to the FAO. The provided data should be reviewed through the International Plant Protection Convention governing bodies and structure. This is the basis to create or expand an ISPM to include this treatment modality.

\section{Summary}

The EB Treement team appreciated the exploratory process and conversations with all our interviewees. The program allowed us to travel down paths we were not expecting and gave guidance on when to turn back. Our value proposition did not differ too far from its origin, and the BMC along with other visuals kept us focused. In Figure 8 we plotted the genre of interviewees and the cumulative interviews through our time with the program.

The industry provided valuable feedback in which it is searching for a risk adverse, cheaper and efficient treatment modality. The regulators might not be ready for particle accelerators to be that elegant solution. However, the lower carbon footprint of wood-based materials compared to concrete or steel may help drive the regulatory environment forward, in response to international decarbonization mandates.

EB Treement has the potential to minimize the risk of forest invasive species thus reducing carbon emission, substantially reduce the use of Methyl Bromide establishing environmental justice, all while generating a flexible year-round revenue stream for the industry. From the team's perspective, our time to the program was worth the investment and we hope the industry will realize EB Treement could be theirs. 


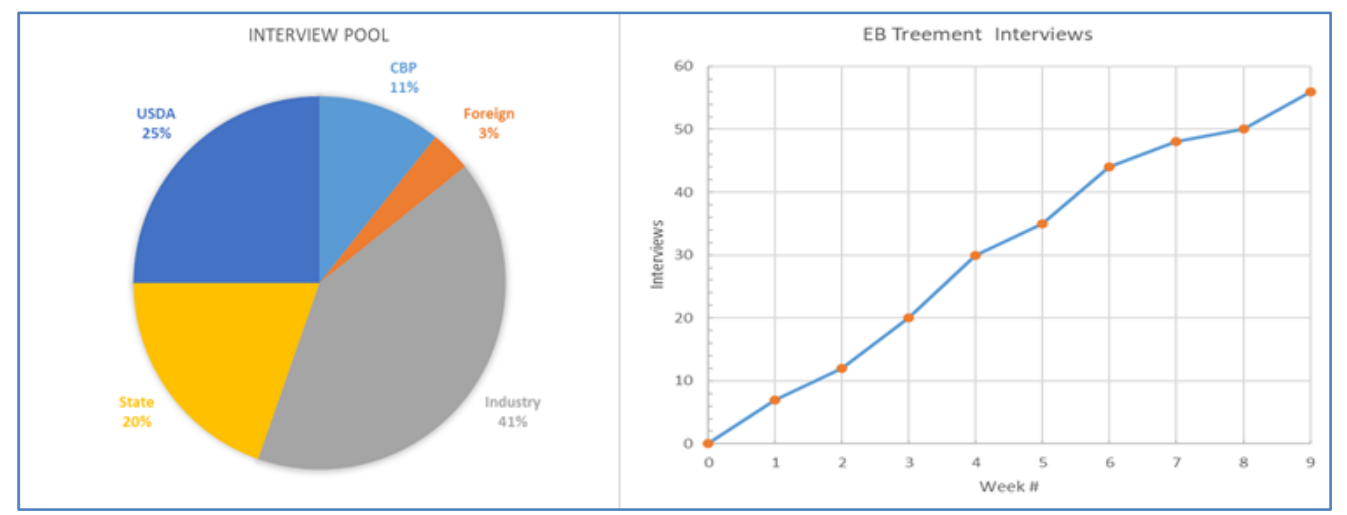

Figure 8: EB Treement's Interview resources and integrated count

\section{Bibliography}

[1] US Department of Energy, "Energy I-Corps," Office of Technology Transitions, [Online]. Available: https://www.energy.gov/technologytransitions/initiatives/energy-i-corps. [Accessed 23 August 2021].

[2] C. Santin, S. H. Doerr, M. W. Jones and G. R. van der Werf, "Global fire emissions buffered by the production of pyrogenic carbon," Nature Geoscience, vol. 12, no. 9, pp. 742-747, 2019.

[3] nature, "Concrete needs to lose its colossal carbon footprint," nature, vol. 597, pp. 593-594, 28 September 2021.

[4] Debating Science, "Debating Science," Univeristy of Massachusetts, 21 April 2016. [Online]. Available: https://blogs.umass.edu/natsci397a-eross/what-building-material-wood-steel-concrete-has-the-smallestoverall-environment-impact/. [Accessed 2010 2021].

[5] USDA Forest Service, "Major Forest Insect and Disease," FOREST HEALTH PROTECTION, 2020.

[6] Convention, Secretariat of the International Plant Protection, "Regulation of wood packagin material in international trade," in ISPM 15, 2019.

[7] Convention, Secretariat of the International Plant Protection, "Guidelines for the use of irradiation as a phytosanitary measure," in ISPM 18, 2019.

[8] Convention, Secretariat of the International Plant Protection, "Phytosanitary treatments for regulated pests," in ISPM 28, 2016.

[9] PPQ, "Plant Protection Today - In Trade Negotiations, Plant Health Issues Get Technica," USDA-APHIS-, 28 May 2020. [Online]. Available: https://www.aphis.usda.gov/aphis/ourfocus/planthealth/ppq-programoverview/plant-protection-today/articles/us-china-trade-deal. [Accessed 2020].

[10] Forest Inventory and Analysis, "National Forest Type Groups," USFS, 1992.

[11] B. J. Brett, S. M. Butler, J. Caputo, J. Dias, A. Robillard and E. M. Sass, "Family forest ownerships of the United States, 2018: results from the USDA Forest Service, National Woodland Owner Survey," U.S. Department of Agriculture, Forest Service, NRS, Madison, WI, 2021.

[12] United States Department of Agriculture, "Treatment Manual," 2016.

[13] J. Wayland, "National Rail Network Map," ArcGIS, 2021.

[14] European Union, "COMMISSION IMPLEMENTING REGULATION (EU) 2019/2072," Official Journal of the European Union, vol. 319, no. II, p. 167, 2019. 